\title{
LETRAMENTO ACADÊMICO: A PRÁTICA DA LEITURA NO DESENVOLVIMENTO ACADÊMICO DE ALUNOS DO CURSO DE ENGENHARIA CIVIL
}

\author{
ACADEMIC LITERACY: THE PRACTICE OF READING IN THE ACADEMIC \\ DEVELOPMENT OF STUDENTS OF THE CIVIL ENGINEERING COURSE
}

\begin{abstract}
Felipe Correa da Rosa Leite Especialista em Docência do Ensino Superior, Centro Universitário da Região da Campanha - URCAMP Bagé, RS - Brasil eng.felipeleite@hotmail.com
\end{abstract}

\begin{abstract}
Veronice Camargo da Silva Doutora em Letras, área de concentração linguística aplicada, Universidade Estadual do Rio Grande do Sul - UERGS Osório, RS - Brasil veronice-silva@uergs.edu.br
\end{abstract}

\begin{abstract}
Resumo: A presente pesquisa trata-se de um estudo sobre a prática da leitura e da escrita objetivando analisar de que forma as práticas de letramentos acadêmicos podem implicar no desempenho dos acadêmicos de um curso de Engenharia Civil. A metodologia tem como base a pesquisa aplicada mista, utilizando questionários, aplicados com setenta e cinco alunos do curso de Engenharia Civil do Centro Universitário da Região da Campanha, RS. A análise quanto ao propósito da leitura é pertinente, uma vez que os alunos salientaram sua relevância, pois aprimora o vocabulário e permite uma melhor comunicação e uma melhor escrita. Já para a presença da leitura nos cursos de engenharia, os alunos ressaltam que contribui para a interpretação e resolução de cálculos. Dessa forma, é perceptível que os alunos que demonstraram ler mais, apresentaram melhor desenvoltura na escrita de suas respostas, enquanto os que não leem, apresentaram dificuldades em responder as questões propostas.
\end{abstract}

Palavras-chave: Letramento acadêmico. Engenharias. Leitura. Escrita.

Abstract: This research is a study on the practice of reading and writing aiming to analyze how academic literacy practices can imply in the performance of students in a Civil Engineering course. The methodology is based on mixed applied research, using questionnaires, applied to seventy-five students from the Civil Engineering course at the University Center of the Campanha Region, RS. The analysis regarding the purpose of reading is pertinent, since students stressed its relevance, as it improves vocabulary and allows for better communication and better writing. As for the presence of reading in engineering courses, students emphasize that it contributes to the interpretation and resolution of calculations. Thus, it is noticeable that the students who demonstrated to read more, presented better resourcefulness in the writing of their answers, while those who did not read, had difficulties in answering the proposed questions.

Keywords: Academic Literacy. Engineering. Reading. Writing.

\section{Para citar - ABNT NBR 6023:2018}

LEITE, Felipe Correa da Rosa; SILVA, Veronice Camargo da. Letramento acadêmico: a prática da leitura no desenvolvimento acadêmico de alunos do curso de engenharia civil. Cadernos de Pós-graduação, São Paulo, v. 19, n. 2, p. 207-220, jul./dez. 2020. Disponível em: https://doi.org/10.5585/cpg.v19n2.18290. 
Introdução

A prática de escrita em contextos acadêmicos, de acordo com Lea e Street (2006, p. 368369, tradução nossa), pode ser conceituada através de três modelos ou perspectivas. O primeiro, trata do modelo de habilidades de estudo que "vê a escrita e a alfabetização como uma habilidade individual e cognitiva". O segundo, é denominado como socialização acadêmica. Este modelo "preocupa-se com a aculturação dos alunos em discursos e gêneros disciplinares e baseados em disciplinas". O terceiro modelo, que é denominado letramento acadêmico, "preocupa-se com a criação de significado, identidade, poder e autoridade e coloca em primeiro plano a natureza institucional do que conta como conhecimento em qualquer contexto acadêmico específico".

Para que haja a desenvoltura da escrita, é primordial o hábito da leitura como prática social, que é um fator determinante na aprendizagem acadêmica, porém, ela vem se perdendo no decorrer dos anos com a inserção de novas tecnologias, pois de certo modo elas dispersam o leitor. Esta questão é reforçada por Figueiredo (2016) ao dizer que muitos dos leitores ativos, sejam eles novos ou mais experientes, têm dedicado uma maior parte do seu tempo ao celular e eletrônicos em geral o que, consequentemente, diminui o tempo que poderia ser dedicado à leitura.

Ao ingressar na universidade, o aluno deve compreender que é preciso se inserir em práticas de leitura e escrita que fazem parte do seu cotidiano acadêmico. A partir disso, estará em contato com o letramento acadêmico, que segundo Fischer (2008, p. 180), "refere-se à fluência em formas particulares de pensar, ser, fazer, ler e escrever, muitas das quais são peculiares a um contexto social".

Os Cursos de Engenharias em geral, objeto de análise do presente estudo, apresentam uma grande demanda de disciplinas de cálculo e estas requerem não somente serem entendidas como compreendidas. Para essa compreensão, é fundamental a interpretação dos temas propostos e, para que isso seja realizado, faz-se necessário ter práticas de leitura, as quais determinam a aquisição da capacidade de ler, interpretar e decodificar o que é proposto. Com a falta das práticas letradas, obtêm-se uma dificuldade significativa nesse processo.

É de suma importância compreender a relevância que a prática da leitura pode proporcionar aos indivíduos, de como através dessa prática pode dar autonomia a alguém que, ao ler sobre determinando tema, adquire a capacidade de compreender e saber argumentar, de obter o conhecimento e saber se expressar.

É possível, então, obter a seguinte problematização: de que forma as práticas de leitura que emanam da proposta de letramento acadêmico podem contribuir para desenvolver a capacidade de ler e interpretar as propostas apresentadas pelos professores aos alunos dos Cursos de Engenharia? 
A partir deste questionamento, o objetivo geral constitui-se em analisar de que forma as práticas de letramentos acadêmicos podem implicar na vivência e desempenho dos acadêmicos de um curso de Engenharia Civil.

Além disso, como objetivos específicos, tem-se: constatar as práticas de leitura realizadas buscando compreender o perfil dos alunos; relacionar o propósito da leitura e identificar sua contribuição para uma melhor escrita; verificar a presença da leitura no campo das engenharias e como ela pode contribuir para um melhor desenvolvimento acadêmico.

\section{Referencial teórico}

\section{A leitura como ferramenta do conhecimento}

De acordo com Aguiar (1996), a prática da leitura não é tão habitual nos dias de hoje e, complementa ainda, que as pessoas aprendem o código escrito, tendo domínio em todos os seus gêneros que encontramos nas práticas como, por exemplo, as propagandas, receitas, notícias; e também nas estéticas, como narrativas e poemas.

No Brasil, estudos revelam que a situação não é uma das mais favoráveis no que diz respeito à leitura. Segundo Jardon (2007), mais de 50\% dos estudantes brasileiros apresentam dificuldades para utilizar a leitura como ferramenta para o conhecimento de outras áreas. Isso quer dizer que a falta da leitura no cotidiano dos indivíduos propicia dificuldade ao usá-la para ampliar os conhecimentos, justamente por não haver esse contato mais presente no dia a dia.

É possível compreender que a leitura proporciona diversos benefícios, já que através dela é possível ter um melhor raciocínio que possibilita interpretar determinado tema e, consequentemente, se posicionar sobre os fatos através do conhecimento.

Com isso, Silva (1996, p.42) busca conceituar através da realidade educacional brasileira, as diversas funções que a prática da leitura possibilita:

Leitura é uma atividade essencial a qualquer área do conhecimento e mais essencial ainda a própria vida do ser humano. [...] está intimamente relacionada com o sucesso acadêmico do ser que aprende; e, contrariamente, à evasão escolar.

O referido autor defende que é através da leitura que as pessoas podem se tornar sujeitos pensantes, de se situar ao meio e serem capazes de compreender e argumentar sobre determinado tema, de ter um pensamento crítico e poder redigir um texto com facilidade. É através da leitura que o indivíduo pode se tornar um ser autônomo, ampliando cada vez mais os conhecimentos.

A leitura é capaz de mudar um indivíduo, moldando-o através dos seus conhecimentos e dos seus aprendizados. Dessa maneira, a leitura não é somente algo para o nosso entretenimento, 
tampouco um método de se obter o conhecimento, mas uma ferramenta que nos molda e nos transforma.

O leitor autêntico é aquele que busca não somente ler, mas que se apropria da leitura, buscando a compreensão da escrita. Nessa direção, Andaló (2000, p. 48) descreve que o verdadeiro leitor "busca entender o que está escrito, mobilizando tudo o que sabe sobre a língua: o sistema de escrita, as características do gênero, o suporte ou portador do texto, o assunto ou tópico, o contexto, o autor e sua época”.

É visto que a leitura tem um papel fundamental na vida de cada indivíduo porque pode contribuir para uma melhor compreensão das coisas que ocorrem ao seu redor. A leitura proporciona uma transformação ao leitor, tendo em vista que este leitor adquire diversos conhecimentos tornando-o um sujeito capaz de argumentar sobre determinado tema, a partir do conhecimento previamente obtido.

\section{Letramentos acadêmicos e a interpretação de elementos textuais}

Falar sobre a leitura e sua prática, remete a reflexões sobre o quanto a leitura e o letramento se interligam, portanto, busca-se o entendimento do que é o letramento e de que não basta somente decodificar os elementos textuais, mas se apropriar da escrita de modo a entender e compreender o que está sendo lido.

De acordo com a afirmação de Fischer (2007, p. 12), é através do convívio no ambiente acadêmico, "das formas de orientação de letramento pelos professores e de concepções-base desses profissionais [...], que é possível aos alunos construírem tipos específicos de letramentos acadêmicos".

O letramento está diretamente relacionado tanto com a linguagem quanto com a escrita, sendo um senso comum que é compartilhado entre as pessoas, porém espera-se também que as pessoas consideradas letradas, tenham um domínio e possuam uma fluência na língua falada (GARTON e PRATT, 1989, tradução nossa).

Dessa forma, uma pessoa que possua uma prática de leitura e um conhecimento amplo do vocabulário, espera-se também que ela tenha um domínio ao se expressar do modo falado.

Segundo os autores Rinck, Boch e Assis (2015, p. 16), um dos maiores desafios encontrados nas pesquisas atuais sobre o letramento se refere, principalmente, aos recém-chegados nas universidades o que exige compreender que há uma transição entre a saída do ensino médio e a entrada na universidade e que a inserção da escrita acadêmica não é feita de maneira automática. Deve ser feita uma inserção gradual e os alunos devem se familiarizar com textos universitários, de modo 
que deverão ler e escrever sobre temas específicos para que aos poucos se apropriem, buscando como retorno não apenas saberes, mas que por meio da escrita sejam capazes de pensar.

Soares (2003, p. 92) destaca que o letramento possui diversas competências, sendo a "capacidade de ler ou escrever para atingir diferentes objetivos, [...] para ampliar conhecimentos, [...] habilidades de interpretar e produzir diferentes tipos de gêneros de textos". Isso somado ao prazer de ler e escrever, de buscar novos conhecimentos e se apropriar deles, tornando um indivíduo diferenciado, capaz de ler e escrever sobre suas compreensões, sabendo se expressar de forma clara e suscinta.

O indivíduo que lê, seja um livro, um artigo ou um material acadêmico e que mantém essa prática, terá muito mais facilidade na escrita, como também de codificar e decodificar os elementos textuais além de se apropriar e compreender o que se está lendo.

Através das práticas da leitura e escrita é que o letramento se desenvolve para que o leitor tenha domínio da língua e possa compreender o que está lendo, a fim de conhecer as regras básicas dos gêneros textuais e não apenas ler, mas codificar, decodificar e compreender o texto que se lê e, com isso, possa discutir qualquer tema lido com a segurança de que houve um ganho no conhecimento através da compreensão.

\section{A presença da leitura e escrita dentro dos cursos de engenbaria}

Independente da área de estudo, todas necessitam da leitura e da escrita. Alguns cursos possuem mais, outros menos, porém as práticas da leitura e escrita devem sempre estar presentes nos estudos universitários. O campo das Engenharias faz parte da área de exatas e apresenta como base de estudos, os cálculos. Porém, para a realização desses cálculos deve haver leitura e interpretação de textos informativos que dão um norte para desenvolver o que é proposto. O engenheiro deve em sua vida profissional ter domínio da língua escrita e falada para desenvolver melhor sua profissão e isso só será possível, com as práticas da leitura, da escrita e da fala.

Para Heinig e Franzen (2012), não basta para o engenheiro ter raciocínio lógico e técnico para desempenhar sua profissão, é mais que isso: o profissional deve interagir, utilizar a linguagem de maneira correta, ser capaz de redigir um texto de maneira adequada, além de saber escolher leituras e materiais que sejam importantes para o cotidiano na profissão. São esses fatores que fazem o diferencial de um profissional e essas são as competências que estão sendo mais exigidas no campo profissional nos dias de hoje.

Para que seja possível o profissional ter um domínio e atender as competências exigidas, são fundamentais práticas da leitura e escrita que devem vir dos estudos proporcionados na universidade. Assim, segundo Russel (2009, p. 242), 
A escrita na universidade é algo bastante especializado, muito mais especializado do que na escola secundária. Os alunos devem aprender a usar vocabulários especializados (com frequência, passamos boa parte de uma disciplina introdutória [dada] na universidade, ensinando terminologia e conceitos).

O aluno ingressante à vida acadêmica possui uma vivência pré-estabelecida, portanto, ele já contempla vivências de letramentos, ainda que estes não sejam voltados para o lado acadêmico. É necessário compreender que os alunos enfrentarão dificuldades ao introduzir o letramento acadêmico em seu cotidiano, mas deve ser estabelecido que esse processo é fundamental.

De acordo com Fischer (2007), no contexto sociocultural, que envolve tanto os alunos quanto os professores, é possível compreender quais as dificuldades que alunos que ingressam na universidade possuem, porque elas se manifestam dessa maneira e a partir disso, o que será considerado como alternativa de transformação do aluno.

No que diz respeito às práticas de leitura e escrita, Dionísio et al. (2011, p.96) comenta que:

Ler e escrever são tarefas particularmente complexas, que têm de ser ensinadas e promovidas sistemática e intencionalmente em todos os níveis de ensino e em todas as disciplinas e, por outro lado, que o desempenho acadêmico não é apenas uma questão de conhecimento de conteúdo, mas também e muito, de saber compreender e produzir os textos em que se transmite tal conteúdo.

Os gêneros textuais/discursivos que buscam possibilitar a estimulação quanto a postura crítica do aprendiz estão intimamente ligados à atuação no campo da Engenharia. Cada prática cotidiana requer contato com os gêneros característicos do fazer profissional do engenheiro. Muito além de entrar em contato ou decodificar esses gêneros, a rotina exige que o engenheiro os produza e interprete-os. Alguns gêneros são recorrentes na esfera de atuação profissional na área de Engenharia e cada um deles tem uma função dentro da rotina de trabalho. E, embora se pense no curso de Engenharia como de atividades puramente exatas, ele requer habilidades como leitura, interpretação e produção de textos (SCHLICHTING, HEINIG, 2011).

Com a preocupação da formação de um profissional mais abrangente, nos cursos de engenharia, a formação básica de um engenheiro não pode apenas se limitar ao conhecimento de termos técnicos e específicos de sua área. Deve abranger também algumas outras competências, buscando o aluno desenvolver novas habilidades ao ramo profissional.

De acordo com Fischer (2011, p. 54), “o aprender fazendo e o aprender com base em modelos passados têm se mostrado os meios mais eficazes para que alunos comprovem maior fluência nas práticas envolvendo leitura e escrita". Ou seja, somente através da prática da leitura e escrita é que os alunos terão a capacidade de ser mais críticos e terem a possibilidade de argumentar. 
Os cursos de engenharia, ainda que possuam muitas disciplinas das exatas, devem reconhecer que a formação de um engenheiro não deve se limitar apenas aos termos técnicos e específicos de sua área. Espera-se que o engenheiro seja capaz de desenvolver não só novas habilidades, mas que se torne um leitor crítico, não apenas daquilo que se lê, mas também das circunstâncias e situações que ele virá a enfrentar em sua vida profissional.

Para as práticas letradas, o professor será uma peça chave, pois irá buscar de meios para incentivá-los na leitura e escrita, tendo em vista a demonstração para seus alunos que essa prática será muito importante para o futuro deles e que facilitará na comunicação, no modo de se expressar e saber como lidar e se impor em determinadas situações.

\section{Caminhos metodológicos}

A pesquisa é de natureza aplicada e pode ser considerada como um estudo misto, já que os resultados obtidos tanto definirão a qualidade do que se está procurando obter, mas também a quantidade de alunos com a prática da leitura.

Quanto à abordagem dos objetivos, ela é classificada como uma pesquisa descritiva e explicativa. Gil (2008, p. 28) relata que a pesquisa descritiva se remete a "descrição das características de determinada população ou fenômeno ou o estabelecimento de relações entre variáveis. [...] salientam-se aquelas que têm por objetivo estudar as características de um grupo". Enquanto isso, o autor determina que as pesquisas explicativas são:

\footnotetext{
Aquelas pesquisas que têm como preocupação central identificar os fatores que determinam ou que contribuem para a ocorrência dos fenômenos. Este é o tipo de pesquisa que mais aprofunda o conhecimento da realidade, porque explica a razão, o porquê das coisas (GIL, 2008, p. 28).
}

Para levantamento de dados, os sujeitos que fazem parte do estudo são acadêmicos do Curso de Engenharia Civil do Centro Universitário da Região da Campanha - Urcamp, campus Bagé, RS. Essa escolha se deu por ser o curso de graduação de um dos autores, além de o curso, por ser integrante da área das exatas, tem um percentual considerável de disciplinas que envolvem cálculos e buscou analisar se há a presença da leitura no cotidiano dos alunos.

Para a coleta de dados, foi aplicado um questionário, contendo questões semiabertas e fechadas, junto ao termo de consentimento, no qual evidenciava o propósito da pesquisa, garantindo o sigilo dos dados pessoais dos participantes. Destaca-se que a pesquisa foi conduzida de acordo com as normas éticas de pesquisa científica definidas pelos organismos internacionais.

O questionário foi entregue aos acadêmicos de todos os módulos vigentes no período de aplicação, que se deu entre os dias 23 e 30 de setembro de 2019, buscando abranger o máximo 
possível de alunos do curso. Foram coletados setenta e cinco questionários, numerados para facilitar a organização das respostas, sem identificar os sujeitos. Os dados foram separados em três tópicos: a) perfil dos alunos); b) propósito da leitura e sua contribuição para a escrita e c) influência da leitura nos cursos de engenharia.

Para o tópico referente ao "propósito da leitura e sua contribuição para a escrita" foram selecionadas respostas de 5 sujeitos (identificados pelos números 3, 7, 29, 57 e 59) e para o tópico "influência da leitura nos cursos de engenharia" foram selecionados 4 acadêmicos (numerados como 7, 41, 44 e 60). Salienta-se que não foi utilizado nenhum critério para a seleção diferenciada de alunos, buscando as respostas que mais contribuíam para os objetivos propostos, pois alguns alunos não responderam as questões discursivas.

\section{Resultados e discussões}

Perfil do Aluno

O perfil dos alunos, com base nos resultados obtidos, os quadros 1 e 2 apresentam a opinião sobre as práticas de leituras e a quantidade de livros lidos, respectivamente.

Quadro 1 - Opinião sobre as práticas de leituras

\begin{tabular}{|c|c|c|c|}
\hline \multicolumn{4}{|c|}{ Opinião sobre a práticas de leituras } \\
\hline Gosto muito & Gosto & Não gosto & Indiferente \\
\hline $9,33 \%$ & $62,67 \%$ & $18,67 \%$ & $9,33 \%$ \\
\hline
\end{tabular}

Fonte: $\mathrm{O}$ autor.

Quadro 2-Quantidade de livros lidos nos últimos seis meses

\begin{tabular}{|c|c|c|c|c|}
\hline \multicolumn{5}{|c|}{ Livros lidos nos últimos seis meses } \\
\hline Nenbum & 1 & 3 a 4 & 5 a 6 & Mais de 6 \\
\hline $34,66 \%$ & $36,00 \%$ & $20,00 \%$ & $6,67 \%$ & $2,67 \%$ \\
\hline
\end{tabular}

Fonte: $\mathrm{O}$ autor.

Desse modo, mostra-se oportuno compreender e analisar os tipos de leituras que os alunos estão buscando. Assim, o quadro 3 retrata a frequência das leituras dos alunos. 
Quadro 3 - Frequência de leituras em relação à cada instrumento

\begin{tabular}{|l|c|c|c|c|c|}
\cline { 2 - 6 } \multicolumn{1}{c|}{} & \multicolumn{5}{c|}{ Frequência de leituras } \\
\hline \multicolumn{1}{|c|}{ Instrumento } & Diariamente & Semanalmente & Mensalmente & Anualmente & Nunca \\
\hline Jornais & $22,67 \%$ & $30,67 \%$ & $13,33 \%$ & $9,33 \%$ & $24,00 \%$ \\
\hline Livros Acadêmicos & $20,00 \%$ & $30,67 \%$ & $32,00 \%$ & $12,00 \%$ & $5,33 \%$ \\
\hline Livros em geral & $17,33 \%$ & $17,33 \%$ & $18,68 \%$ & $33,33 \%$ & $13,33 \%$ \\
\hline
\end{tabular}

Fonte: $\mathrm{O}$ autor.

Desta maneira, foi indispensável averiguar qual seria a principal barreira na qual impede o hábito da leitura, estas apresentadas no Quadro 4:

Quadro 4 - Barreiras que impedem o hábito da leitura

\begin{tabular}{|c|c|c|c|}
\hline \multicolumn{4}{|c|}{ Barreiras que impedem o hábito da leitura } \\
\hline Tempo & Lentidão na leitura & Condições Financeiras & Outros \\
\hline $76,00 \%$ & $9,33 \%$ & $2,67 \%$ & $12,00 \%$ \\
\hline
\end{tabular}

Fonte: $\mathrm{O}$ autor.

\section{O propósito da leitura e sua contribuição na escrita}

É evidente que a leitura é importante, independente da área de atuação e, através dela é possível obter uma melhor escrita. Portanto, é fundamental compreender a perspectiva dos alunos através dessa concepção. Os sujeitos foram questionados sobre qual o propósito da leitura e se ela pode proporcionar uma melhor escrita.

Com base nas respostas obtidas através da aplicação do questionário, o propósito da leitura é um meio para agregar conhecimento, contribuir para o desenvolvimento dos indivíduos, tanto na forma pessoal quanto profissional. A leitura possibilita compreender que o mundo está em constante evolução e que há sempre algo novo para aprender.

Além disso, é possível obter um senso crítico sobre os mais variados temas, sendo capaz de abordar e opinar com uma melhor desenvoltura. Destaca-se o aluno 3 que contribui com a seguinte observação: "ler é vida e a vida sem leitura é uma vida sem conhecimento".

Tendo em vista que a leitura contribui para o conhecimento e ajuda numa melhor aprendizagem, o aluno 7 comenta que "quanto mais uma pessoa lê, mais conhecimento adquire e é capaz de produzir textos mais elaborados". Já o aluno 29 descreve que "ler desenvolve o vocabulário e a leitura pode dar uma visão de como se escrevem corretamente as palavras".

O aluno 57 comenta que a leitura contribui para "elevar a intelectualidade e organiza os pensamentos e o modo de se expressar". O aluno 59 reforça que "quanto maior o contato com textos, mais se terá facilidade de produzir os seus próprios”. 
Com base nos relatos dos alunos, é possível compreender que através da leitura se está “contribuindo para a formação de leitores mais autônomos e competentes, sem pensar em leitura como obrigação escolar, mas como ferramenta à qual se adquire conhecimento para uma vida (ZULIM, 2011, p. 23)"'.

Em relação aos alunos 7 e 29, a leitura de fato contribui para um vocabulário mais elaborado, porém o aluno deve procurar saber os significados de palavras desconhecidas para que haja uma leitura mais fluida. Baldo (2008, p. 289) retrata que

\footnotetext{
Com base em nossa experiência como leitores, sabemos que, sem o conhecimento do significado das palavras presentes no texto, o processo de compreensão sequer inicia. Ainda que outros fatores estejam implicados na compreensão leitora, o conhecimento de vocabulário tem um caráter único na medida em que ele é o responsável pelo desencadeamento de outros processos específicos de compreensão.
}

Para obter um melhor resultado na escrita acadêmica, o aluno precisa ter mais contato com leituras acadêmicas, que irão retratar de termos que poderão ser melhor utilizados nos seus textos futuros. Para tanto, a partir dos pensamentos dos alunos 57 e 59, Snow e Ucelli (2008, tradução nossa) relatam que a linguagem acadêmica é mais difícil do que outros estilos de linguagem, e buscar formular abordagens para a linguagem acadêmica é necessário não somente para o alcance em domínios associados a linguagem, mas também para o alcance em matemática e outras áreas que a linguagem se faz necessária.

É possível notar que mesmo que o aluno não demonstre o contato diário com a leitura, reconhece que a presença da leitura provoca diversas mudanças, tanto na maneira de se expressar, quanto de obter uma escrita mais clara.

\section{A influência da leitura nos cursos de engenharia}

A presença da leitura como já apontado anteriormente, contribui para uma melhor escrita, em que os indivíduos adquirem conhecimento de novos assuntos, estando sempre atualizados, e, na engenharia, isso não é diferente.

Apesar de ser um curso voltado para as exatas, muitos acreditam que a leitura pode ser dispensada, como explana o aluno 7, dizendo que "em geral as engenharias são voltadas para a área de cálculo, não possuindo foco na leitura”.

Em contrapartida a esse pensamento, o aluno 41 explica que "todo o conhecimento de cálculo vem do embasamento teórico, ou seja, para entender o cálculo é necessário entender a teoria”. Isso comprova que, mesmo em disciplinas que dependam principalmente de cálculos para 
serem desenvolvidas, a leitura, a compreensão e a interpretação dos métodos estão presentes para que esses cálculos sejam realizados.

Além da compreensão das normas, com base no relato do aluno 60 , retrata que a leitura contribui para uma melhor escrita de artigos científicos, determinando uma linguagem mais formal, também contribuindo para a apresentação de trabalhos, em que o emprego correto das palavras, sendo de forma clara e coesa, são pontos determinantes de uma boa apresentação.

É possível perceber que a leitura pode proporcionar uma melhor competência no ramo de atuação, auxiliando diretamente na vida profissional e contribuindo para ter um conhecimento mais vasto e um vocabulário mais amplo para auxiliar na comunicação. Assim, o aluno 44 relata que "a leitura melhora a capacidade de se expressar, e como o engenheiro pode ocupar cargos de liderança, é fundamental para a vida profissional".

Em relação ao relato do aluno 7, Heinig e Santos (2011) retratam que esse é o pensamento dos alunos que estão mais no início da graduação das áreas exatas, mas que no decorrer do curso, acabam revendo seus pensamentos e reconhecendo a necessidade da leitura em suas profissões.

Ao associar o pensamento do aluno 41, Bakhtin (2010, p. 261), ressalta que todos os “campos da atividade humana estão ligados ao uso da linguagem". Assim sendo, por mais que as engenharias tenham uma relação direta ao ramo das exatas, práticas de leitura e interpretação são fundamentais para a resolução de cálculos.

Heinig e Santos (2011, p. 74) relacionados ao relato do aluno 60, defendem que experiências de pesquisa, produção de artigos e trabalhos de conclusão encaminham-se para "reflexões sobre o letramento no processo de formação desses profissionais e para a necessidade de adequações e melhorias na forma como ocorre o ensino-aprendizagem da leitura e da escrita no seu curso".

Em conformidade com o aluno 44, Bazzo e Pereira (1997), discorrem sobre o assunto da vida profissional, dizendo que o engenheiro necessita saber se comunicar e que a comunicação escrita é fundamental para o seu trabalho.

Sob este olhar, pode ser visto que o letramento acadêmico, em especial nos cursos de engenharia, faz-se primordial à compreensão dos variados temas e, futuramente, irá contribuir para um melhor desempenho na vida profissional.

\section{Considerações finais}

Através dos dados obtidos e analisados, pode-se compreender sobre como se mostra o perfil do aluno do curso de Engenharia Civil, dentro da Instituição de Ensino Superior que foi objeto desse estudo. Com base nas suas práticas letradas, também pode se perceber de que maneira os alunos veem a importância do propósito da leitura e o quanto ela pode contribuir para uma 
escrita mais elaborada. Também pode ser visto o que os alunos compreendem pela leitura dentro do curso de engenharia e o quanto essa prática pode contribuir para um melhor desempenho na vida acadêmica.

Através do perfil do aluno, foi possível perceber que a maior parte do público-alvo demonstrou ter o gosto pela leitura. Em contrapartida, a presença da leitura no cotidiano ainda é muito pouco, principalmente de leituras acadêmicas, que são primordiais para o desenvolvimento acadêmico dos alunos, para que futuramente possibilite a eles desempenhar sua profissão com maior desenvoltura.

Com base na análise dos resultados quanto ao propósito da leitura e sua contribuição para uma melhor escrita, é visto que os alunos reconhecem a importância da prática da leitura e confirmam que essa prática contribui e muito para uma melhor escrita, sendo mencionado que pode proporcionar não somente uma melhor escrita acadêmica, para elaboração de trabalhos, mas também uma melhor desenvoltura ao se expressar, facilitando até mesmo no futuro, em diálogos com possíveis clientes que encontrarão ao longo da profissão. O que confirma a importância de que sejam inseridos em práticas efetivas de letramentos acadêmicos.

Contudo, algo que foi perceptível na análise dos dados é que alunos que responderam que tinham um maior contato com a leitura e que leram um número considerável de livros apresentaram uma escrita mais elaborada para as perguntas que exigiam respostas subjetivas. Por outro lado, os alunos que demonstravam não gostar de ler ou que apresentaram um número baixo de leituras, possuíam uma certa dificuldade em elaborar as respostas, utilizando de poucas palavras, além da presença de alguns erros gramaticais. Vale salientar que em certos questionários alguns alunos, que apresentavam essas características, nem ao menos responderam as questões subjetivas.

Finalmente, com base nos resultados da presença de leitura nos cursos de engenharia, é visto que apesar de alguns alunos afirmarem não ter tanto o contato com leituras acadêmicas e, pelo motivo das engenharias serem mais voltadas ao campo das exatas, foi observado que em grande parte dos alunos afirmam a relevância da prática da leitura, a partir do modelo dos letramentos acadêmicos, dentro da engenharia, já que ela é um intermédio para desenvolver a interpretação de problemas, e só através do embasamento teórico será possível resolver os cálculos propostos. Além do mais, as leituras acadêmicas irão contribuir para uma escrita mais elaborada em trabalhos acadêmicos, tornando seres letrados. Cabe, portanto, à universidade oferecer espaços de leituras e escritas voltadas aos letramentos acadêmicos. 


\section{Referências}

AGUIAR, Vanda T. O leitor competente à luz da teoria da literatura. Revista Tempo Brasileiro, Rio de Janeiro, v. 124, v. 5/6, p.23-34, jan./mar. 1996.

ANDALÓ, A. Didática de língua portuguesa para o ensino fundamental: alfabetização, letramento, produção de texto em busca da palavra-mundo. São Paulo: FDT, 2000.

BAKHTIN, M. Estética da Criação Verbal. 5. ed. São Paulo: WMF Martins Fontes, 2010.

BALDO, Alessandra. As categorias conhecimento e processos de Perfetti na leitura em língua materna: um experimento. Linguagem em (dis)curso, [s.l.], v. 8, n. 2, p.289-310, ago. 2008. FapUNIFESP (SciELO). Disponível em: http:/ /www.scielo.br/scielo.php?script=sci_arttext\&pid=S1518-76322008000200005\&lng=pt\&nrm=iso. Acesso em: 23 nov. 2019.

BAZZO, W. A.; PEREIRA, L. T. do V. Introdução à Engenharia. 5. ed. Florianópolis: Editora da UFSC, 1997.

DIONÍSIO, Maria de Lourdes et al. A leitura e a escrita no currículo: a presença ausente. Atos de Pesquisa em Educaşão, v. 06, p. 94-114. Blumenau. jan/abr. 2011.

FIGUEIREDO, José. A tecnologia não está acabando com a leitura, ela está acabando com os leitores. Disponível em: https://homoliteratus.com/ tecnologia-nao-esta-acabando- com-leitura-ela-esta-acabando-com-leitores/\#disqus_thread. Acesso em: 16 mai. 2019.

FISCHER, A. Letramento Acadêmico: uma perspectiva portuguesa. In: Revista Acta Scientiarum. Language and Culture. Maringá, v.30, n.2, pp. 177- 187, jul./dez., 2008. Disponível em: http://periodicos.uem.br/ojs/index.php/ActaSciLangCult/article/view/2334. Acesso em: 15 nov. 2019.

FISCHER, A. A construção de letramentos na esfera acadêmica. Tese de Doutorado. Programa de PósGraduação em Linguística, Universidade Federal de Santa Catarina. Florianópolis, 2007. Disponível em: https://repositorio.ufsc.br/xmlui/handle/123456789/89764. Acesso em: 15 nov. 2019.

FISCHER, A. Práticas de letramento acadêmico em um curso de Engenharia Têxtil: o caso dos relatórios e suas dimensões escondidas. Scripta, v. 16, p. 54-67, out., 2011.

GARTON, A. e PRATT, C. Learning to be literate: The development of spoken and written language. New York, Basil Blackwell, 1989.

GIL, Antonio Carlos. Métodos e técnicas de pesquisa social. - 6. ed. - São Paulo: Atlas, 2008.

HEINIG, Otilia L.de O. M., FRANZEN, Bruna, A. A leitura e a escrita nos cursos de engenharia: algumas discussões e propostas. COBENGE: Congresso Brasileiro de Educação em Engenharia. Belém, PA, 2012.

HEINIG, O. L. de O. M.; SANTOS, G. R. O letramento no processo de formação do engenheiro civil. Atos de Pesquisa em Educação, Blumenau, v. 6, n. 1, p.53-78, abr. 2011. Disponível em: http://www.furb.br/atosdepesquisa/. Acesso em: 15 de nov. 2019. 
JARDON, Carolina. Alunos da região Sul têm melhor desempenho no Pisa. 2007. Disponível em: http://g1.globo.com/Noticias/Vestibular/0,MUL203889-5604,00-ALUNOS +DA+REGIAO+SUL+TEM+MELHOR+DESEMPENHO +NO+PISA.html. Acesso em: 10 de jan. de 2019.

LEA, M.R., \& STREET, B.V. The "Academic Literacies" Model: Theory and Applications. Theory Into Practice, 45(4), pp. 368-377, 2006. In: Taylor \& Francis Online. Disponível em: https://www.tandfonline.com/doi/abs/10.1207/ s15430421tip4504_11. Acesso em: 23 nov. 2019.

RINCK, Fanny, BOCH, Françoise, ASSIS, Juliana Alves. Letramento e formação universitária: formar para a escrita e pela escrita. Campinas, SP: Mercado de Letras, 2015. - (Série Ideias Sobre Linguagem).

RUSSEL, D. Letramento acadêmico: leitura e escrita na universidade: entrevista com David Russel. Conjectura, v. 14, n. 2, mai./ago., 2009.

SCHLICHTING, Thais de Souza, HEINIG, Otilia Lizete de Oliveira Martins. A leitura e a escrita nas engenharias: gêneros recorrentes e suas funções, 2011. Disponível em: https:/ /www.tecnoevento.com.br/nel/anais/artigos/art74.pdf. Acesso em: 29 jan. 2019.

SILVA, Ezequiel Teodoro. Fundamentos psicológicos para uma nova pedagogia da leitura. $7^{\mathrm{a}} \mathrm{ed}$ - São Paulo: Cortez, 1996.

SNOW, Catherine E.; UCCELLI, Paola. The Challenge of Academic Language. The Cambridge Handbook of Literacy, [s.1.], p.112-133, out. 2008. Cambridge University Press (CUP). Disponível em: https://www.cambridge.org/core/books/cambridge-handbook-of-literacy/challenge-of-academic-language/F4BE5D3DA86D746F2511B8135603E192. Acesso em: 23 nov. 2019.

SOARES, Magda. Letramento e escolarização. In: RIBEIRO, era Masagão (org.). Letramento no Brasil. São Paulo: Global, 2003. Pt. 2 p.89-115.

ZULIM, Leny Fernandes. Literatura no ensino fundamental: da teoria às práticas em sala de aula. Londrina, PR: Amplexo Editora, 2011. 